\title{
São José do Rio Preto fotografado: Imagética de uma experiência urbana (1852-1910)
}

Airton José Cavenaghi

Doutorando-História/USP

\section{RESUMO}

Este artigo analisa a história social de São José do Rio Preto, entre 1852 e 1910, pelo uso da imagem fotográfica. Propõe mostrar que a fotografia pode ser usada como um mecanismo de construção historiográfica na análise do cotidiano socioeconômico de uma determinada localidade.

Palavras-chave: Fotografia. Urbanização. Interior paulista. São José do Rio Preto. Brasil (século XIX).

\section{ABSTRACT}

This article analyzes the social history of São José do Rio Preto, between 1852 and 1910, through the usage photographic image. It is intend to show that photography can be used as a mechanism to construct the history of the daily socioeconomic analysis of a determined place. Keywords: Photography. Urbanization. Countryside of state of São Paulo. São José do Rio Preto. Brazil (XIXth century).

Analisar a chamada História Regional do território noroeste do Estado de São Paulo, pelo uso da fotografia, pode resultar numa forma diferenciada de contar experiências de sua povoação. Os limites conhecidos do território paulista entre 1837, época da produção do Mappa Chorographico da Provincia de São Paulo, de autoria de Daniel P. Müller, até 1909, com a publicação do Atlas do Brazil, de autoria do Barão Homem de Mello', não iam além dos chamados "Campos de Araraquara". "Sertão desconhecido", "Terrenos occupados por indígenas feroses", "Terreno desconhecido", ou mesmo "Terrenos despovoados": assim era conhecida a região até aproximadamente 1909, na qual, no seu limite mais ao norte, localiza-se a cidade de São José do Rio Preto.

O cotidiano desta região, antes conhecida como boca do sertão, sempre foi restrito à escrita de poucos autores que recuperaram sua história ${ }^{3}$. Analisar a história de São José do R. Preto, ao final do século XIX e início do século XX, pelo uso da visualidade fotográfica, torna-se uma alternativa de conhecimento de um cotidiano nem sempre presente nas análises historiográficas disponíveis.

Esta interpretação, pelo uso da imagem fotográfica, mostra elementos e 
acontecimentos que construíram representações próprias de saberes locais resultantes de uma memória coletiva, que é conseqüência sobretudo da coleta de informações realizada por historiadores locais vinculados às tradicionais correntes historiográficas. Esses historiadores trabalham notadamente com reminiscências pessoais ou com o fruto de memórias orais recolhidas esporadicamente no contato, direto ou não, com as personagens do processo histórico em questão. Sistematizar um ambiente urbano, no caso a cidade de São José do Rio Preto, partindo de sua representação em uma imagem fotográfica, mostra que a iconografia não é um mero auxiliar do textual histórico e sim fruto do mesmo cotidiano do qual também fazem parte as imagens.

A fotografia como forma de representação do ambiente urbano é fruto de um modelo histórico que nasce com o advento da Revolução Científica e Tecnológica da segunda metade do século XIX. Este período, também chamado de $2^{\underline{a}}$ fase da Revolução Industrial, foi marcado tecnologicamente pelo uso da eletricidade, de derivados de petróleo e novos elementos químicos, entre eles os fotossensibilizantes.

Boris Kossoy, em recente trabalho, realiza um grande mapeamento de profissionais de fotografia que atuaram no Brasil entre 1840 e 1910, demonstrando que muitos destes tinham em sua itinerância pelo interior do país extensa clientela. Para o autor,

(...) foram esses desconhecidos viajantes que, com suas pesadas câmeras e estranhos equipamentos, captaram a imagem do indivíduo e do grupo familiar: suas fisionomias, seus ritos de passagem, seus eventos mais representativos. Representações que gravadas nos diferentes suportes fotográficos são vestígios documentais de múltiplas existências: deles próprios enquanto retratistas e de seus retratados. ${ }^{4}$

Na região noroeste da Província, entre 1852 e 1900, então conhecida como Sertão desconhecido, nota-se que determinadas cidades não mapeadas oficialmente pelo Estado eram identificadas, quase que exclusivamente, por figurarem em almanaques mercantis e indicadores econômicos elaborados por iniciativas particulares, para aparentemente suprirem uma lacuna que não estava sendo preenchida pelo Estado.

Abilio A.S. Marques, na abertura de seu Indicador de São Paulo para o anno de 1878, na seção Ao Leitor, comenta:

(...) Entendi, porem, que, fazendo um Indicador de S. Paulo já prestaria um bom serviço, á vista do notavel desenvolvimento e progresso a que, n'estes ultimos 
annos, tem attingido a Capital, dando tambem varias informações relativas a toda Provincia, bem como as auctoridades superiores do Estado. ${ }^{5}$

Nota-se que a própria administração central era beneficiada por informações recolhidas por iniciativas particulares.

Neste âmbito, pode-se destacar o Almanak Administrativo, Mercantil e Industrial da Província de São Paulo para 1857, e os Almanachs da Província de São Paulo, editados anualmente por Jorge Seckler, entre 1885 e $1888 .{ }^{6}$ Estes almanaques trazem informações sobre as populações das cidades da Província, tabelas de profissões e endereços, anúncios, etc., que de certa forma suprem a falta de mecanismos de reconhecimento por parte do Estado nesta região. São José do Rio Preto, cidade fundada em 1852, aparece como uma comunidade desde o Almanak Administrativo, Mercantil e Industrial da Província de São Paulo, elaborado em 1857.

O presente artigo busca recuperar a história social de São José do Rio Preto, tendo como ponto de partida uma específica imagem fotográfica urbana, elaborada no início do século XX. Essa fotografia é bastante significativa na medida em que, aparentemente, é a única imagem restante da urbe relativa ao período que vai da sua fundação, em 1852, e a chegada da estrada de ferro, em 1912, que transformaria radicalmente tal paisagem urbana. Desde 1918, a imagem foi utilizada para retratar a cidade, como se observa na publicação do primeiro álbum fotográfico realizado sobre São José do Rio Preto $^{7}$. Este documento compõe o elemento de partida para buscar solucionar as questões iniciais sobre essa imagem, qual sejam, sua datação e sua autoria.

São José do Rio Preto representou uma das últimas fronteiras a serem exploradas e colonizadas, primeiro, na Província e, depois, no Estado de São Paulo. Durante vários anos, foi conhecida como a "boca do sertão" da região da Alta Araraquarense, ou seja, representava a região posterior à "ponta dos trilhos”, estacionada em Ribeirãozinho (atual Taquaritinga) desde $1901 .^{8}$

A presença da ferrovia em uma cidade próxima e o conceito de última fronteira a ser explorada, reforçam a idéia relacionada à busca de ideais de civilização e de progresso. Esses ideais estavam condicionados às necessidades de uma administração estadual, que ao buscar reconhecer-se territorialmente estruturou-se na propagação de sua idéia de governo. Como afirma Gilmar Arruda:

As preocupações com os espaços internos no país, com suas populações e utilização de seus recursos, remontam ao período imperial mas sofrem uma grande revitalização nos quadros da montagem do chamado estado nacional moderno. Nestes ter- 
mos, a questão colocava-se como uma necessidade de civilizar os sertões, impondo a seus moradores novas concepções de tempo, propriedade e trabalho (...).

A estrutura de questionamento das fotografias apresentadas neste artigo baseia-se no momento referenciado: a República brasileira ainda buscava representação em vários elementos, estruturando conceitos presentes no seu próprio bordão inicial, que na expressão de Boris Kossoy reflete o seu sentido original, pois:

(...) principalmente como a fotografia, enquanto registro expressivo de um cenário urbano, arquitetônico e social em processo de mutação, se vê utilizada pelos meios de comunicação impressa na época, e em que medida se refletirão nessas imagens os anseios de modernidade daquela elite. Existe, nesses primeiros anos do novo regime, uma necessidade imperiosa de exaltação do conteúdo simbólico de ordem e progresso. ${ }^{10}$

A crescente presença de álbuns fotográficos que buscavam por meio da representação fotográfica exaltar o Estado, suas qualidade agrícolas e comerciais, corroboram essa idéia. Uma elite vinculada a tais aspectos representa-se e assim transmite sua realidade atrelada à política republicana.

Neste sentido, por exemplo, tem-se a publicação em fascículos da obra O Estado de São Paulo e seus municípios, de Roberto Capri, que de 1913 até aproximadamente 1918 organizou reportagens fotográficas de diversas cidades do interior do Estado, enaltecendo, em especial, seus aspectos comerciais e agrícolas. ${ }^{11}$

Nota-se que, ao estruturar o momento visível presente na representação fotográfica, o fotógrafo encontrava-se imbuído de aspectos inerentes à sociedade da qual fazia parte. Esses elementos de ordem imaterial são aspectos constitutivos e formulam as bases da representação presente. A cidade é vista pelo olhar do fotógrafo, registrada e eternizada, naquele momento, pelo contexto conduzido pelo autor/ator. A sociedade representada é influenciada ao mesmo tempo que influencia. Assim, a verdade absoluta estampada na fotografia é questionável, na medida em que seu "processo de construção da representação" envolve elementos diversos e possuidores de histórias próprias. ${ }^{12}$

O portentoso trabalho de Daniel Pedro Müller, Ensaio d'um quadro estatístico da Província de São Paulo, publicado em 1838, marca o início de uma política centralizadora para o território da Província, revelando o entendimento de São Paulo como uma região passível de controle.

$\mathrm{Na}$ introdução de seu trabalho, percebe-se a intenção imediata: "O fim da Estatística é dar em geral um conhecimento da extensão, e descripção d'um 
païz, e em particular de sua administração, população, commercio, industria, e produção: pode-se-lhe chamar — um inventário exacto do païz". ${ }^{13}$ A publicação de Müller é considerada como uma das primeiras da Província de São Paulo. Foi editada na Typografia de Costa Silveira, localizada na cidade de São Paulo em 1838, na então Rua de São Gonsalo, n. 14, subseqüentemente Rua do Imperador, de 1846 até 1889, e posteriormente Rua Marechal Deodoro. Esta rua desapareceu com as demolições necessárias à construção da atual Catedral da Sé, entre 1911 e 1912.

A obra de Müller, como aparece em seu título, é composta de inúmeros quadros estatísticos. A primeira parte, intitulada Estatistica geographica e natural, busca resumir a história, a geografia e a biologia da Província. A segunda parte, intitulada de Estatistica politica e civil, resume as informações relativas aos governos, povoações e finanças, do território da Província. Daniel P. Müller também é o autor do primeira obra cartográfica detalhada do território da Província de São Paulo. Trata-se do Mappa Chorographico da Provincia de São Paulo, publicado como extensão de seu Ensaio de um Quadro Estatístico, e gravado em Paris pelo editor Aleixo Orgaizzi, em 1837. É a partir do mapa criado por Müller que se observa quanto a então Província era territorialmente desconhecida, pois em relação à região noroeste não havia nenhuma localidade mapeada.

Posteriormente, em 1875, o então senador do Império, Joaquim Floriano de Godoy, publicou seu trabalho A Província de São Paulo, que apresentava como subtítulo: Trabalho estatístico, histórico e noticioso destinado a exposição industrial de Philadelphia (Estados Unidos) ${ }^{14}$. Este estudo, realizado por ocasião da Exposição Internacional de 1875, explicita, pelo encarte de mapas estatísticos e geográficos, a necessidade de buscar dados representativos da Província de maneira a ampliar o conhecimento necessário à elucidação da extensão do próprio território paulista. É importante destacar que ainda nas primeiras décadas do século XX, os limites entre os Estados de São Paulo e Minas Gerais estavam sendo esclarecidos e negociados.

Em 1878, Manuel Eufrásio de Azevedo Marques organizou e editou uma obra descritiva da Província e, em um verbete, descreveu o arraial de Rio Preto:

Rio-Preto (Rio Preto) - Bairro no município de Araraquara, onde existe criada uma cadeira de instrução pública primária para o sexo masculino. Foi elevado à categoria de vila sob a invocação de São José do Rio Preto, por lei provincial. A paróquia não foi ainda canonicamente provida. ${ }^{15}$

Em 1856, Joaquim Roberto de Azevedo Marques organizou o Almanak Administrativo, Mercantil, e Industrial da Província de São Paulo, publicado 
por dois anos consecutivos. Nesta obra notam-se características semelhantes ao trabalho de Manuel Eufrásio, irmão de Joaquim Roberto de Azevedo Marques, como a classificação e a localização de diversas vilas do interior da Província. Na publicação, figura pela primeira vez o nome de São José do Rio Preto, que na época possuía apenas cinco anos de existência. Nesse período, São José do Rio Preto ainda fazia parte da Comarca de Mogy-Mirim, sendo um “(...) curato da freguezia de Jaboticabal." ${ }^{16}$

Percebe-se que o reconhecimento e a inserção da cidade de São José do Rio Preto tornaram-se importantes para o desbravamento do resto da Província e, depois, Estado. Nesse sentido, a presença da Estrada de Ferro foi fundamental, mostrando como a cidade foi um dos redutos finais de um processo de ocupação. No relatório anual enviado ao Congresso Legislativo, em 14 de julho de 1909, pelo presidente do Estado Dr. M. J. de Albuquerque Lins, o autor comenta:

(...) com o avançamento das estradas de ferro Noroeste e Sorocabana para as regiões despovoadas do Estado, urge tratar de resguardar da invasão de intrusos as terras devolutas existentes. Com esse intuito, criaram-se duas commissões para descriminal-as: uma operando nas comarcas de Agudos e São José do Rio Preto e outra nas de Santa Cruz do Rio Pardo e Campos Novos de Paranapanema. ${ }^{17}$

Oficialmente, o Estado passou a administrar perspectivas de ocupação e mostrou como a mesma deveria seguir: alinhada aos trilhos de uma ferrovia.

Não há nenhuma representação, seja fotográfica ou de outra forma, de São José do Rio Preto, anterior à primeira década do século XX. A imagem

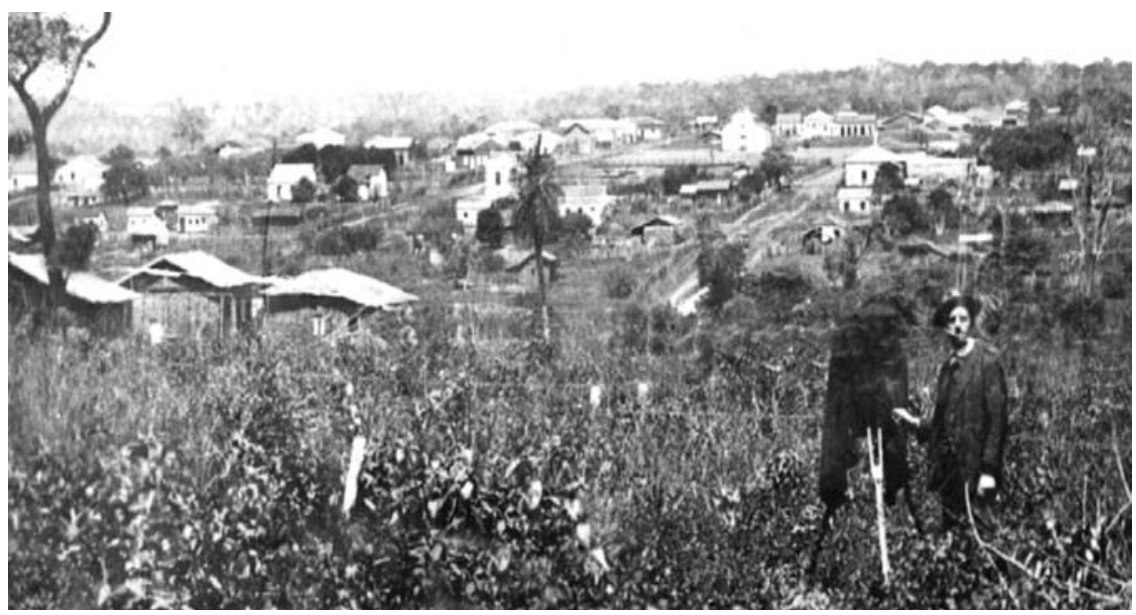

Rio Preto, $1909.8,5 \mathrm{~cm} \mathrm{x} \mathrm{13,5} \mathrm{cm.} \mathrm{(foto} \mathrm{A).}$ 
apresentada a seguir sugere diversas questões, e para tanto constitui-se no objeto de análise central deste artigo. Deve-se sua preservação a Amélia Rodrigues Goulart (1910-2000), antiga moradora da cidade. Segundo a Sra. Amélia, em entrevista concedida em 4/5/1999, a imagem foi dada de presente a seu pai pelo próprio fotógrafo quando ela ainda era menina, aproximadamente na década de 20. Não se detectou a existência de outro exemplar de uma ampliação do negativo original, tanto nos órgãos públicos, como entre particulares (foram consultados na cidade de S. J. do Rio Preto: a CONDEPHAT - Coordenadoria do Departamento do Patrimônio Histórico e Artístico, a Biblioteca Municipal e a Casa de Cultura; na cidade de São Paulo: o Arquivo do Estado e o Instituto Histórico e Geográfico de São Paulo).

Sua primeira publicação é de 1919, no corpo do Álbum de Rio Preto 19181919, (p. 11), sendo esta a mais antiga obra preservada sobre a história da cidade. Esta publicação foi elaborada pelo Dr. Raul Silva, antigo dentista da cidade, segundo Ada Gomes França no Arrolamento das Fontes Históricas de Rio Preto $^{18}$. Neste álbum há um parte histórica escrita pelo Dr. F. Oiticica Lins, advogado na cidade, que revê a história de Rio Preto em conjunto com uma série de três imagens, das quais uma é o objeto central deste artigo (foto A). O conjunto de três imagens do álbum está disposto da maneira como segue abaixo:

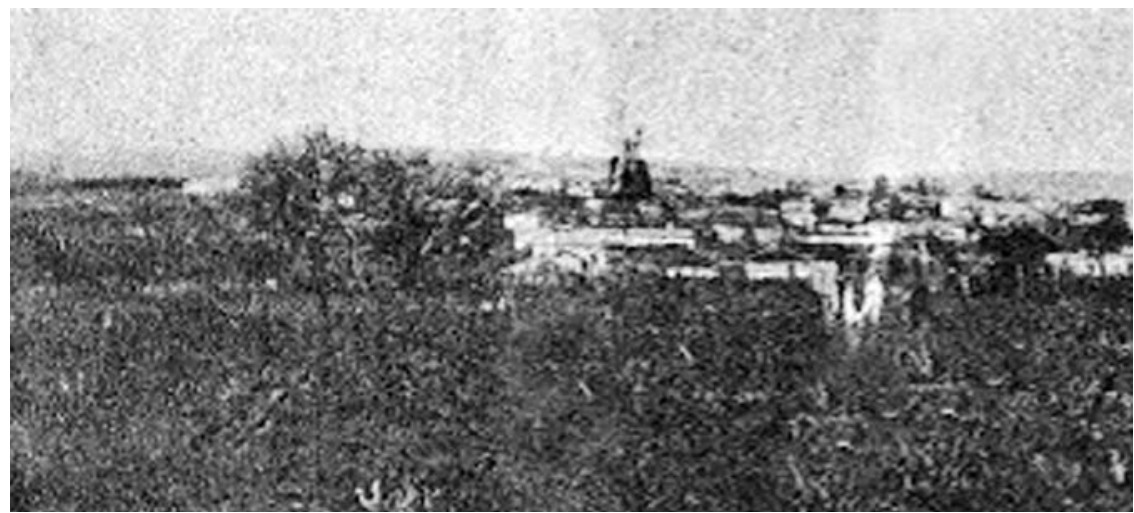

Impressão sobre papel. Álbum de Rio Preto 1918-1919. 5,5 cm X 17 cm. (foto B).

Aparece na p. 6 do álbum, sem nenhuma legenda. Apesar da baixa qualidade de impressão, é possível perceber no centro um conjunto de pessoas como que posando para o registro. Acredita-se que seja uma imagem de São José do Rio Preto, por estar ilustrando a parte histórica do álbum relacionada diretamente à cidade.

Figura na p. 11 do álbum, sendo basicamente a mesma imagem da foto A. 


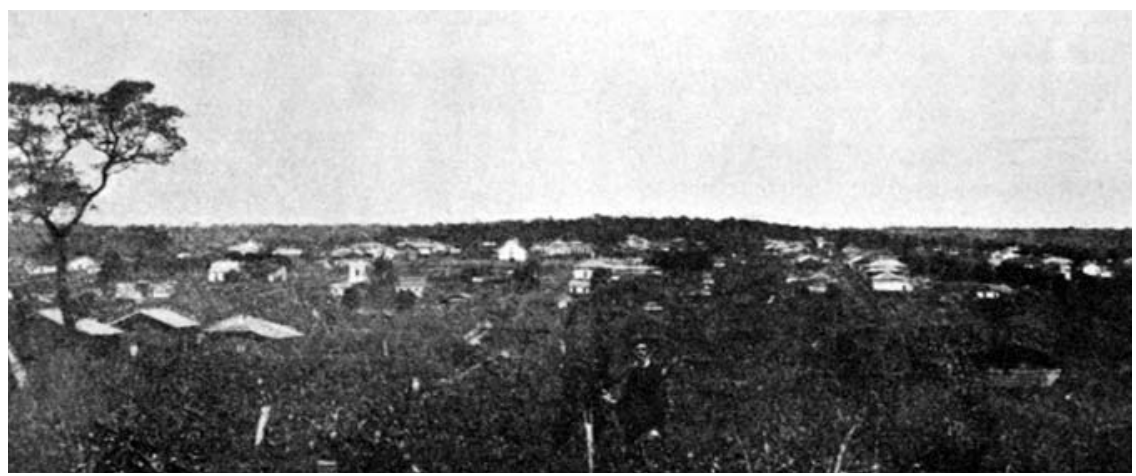

Impressão sobre papel: Álbum de Rio Preto 1918-1919. 7 cm X 17 cm.(foto C).

Não há nesta imagem, como na anterior, nenhuma indicação de data ou autoria. Ambas são partes ilustrativas do textual histórico central.

Localizada na p. 17, é a única que apresenta legenda: "Festa realisada em 1904 commemorando a creação da Comarca de Rio Preto.” A data desta fotografia é corroborada pela reportagem publicada no jornal riopretense O Por$154 v i r$, de 13 de outubro de 1904, que descrevia a festa realizada na cidade nessa ocasião:

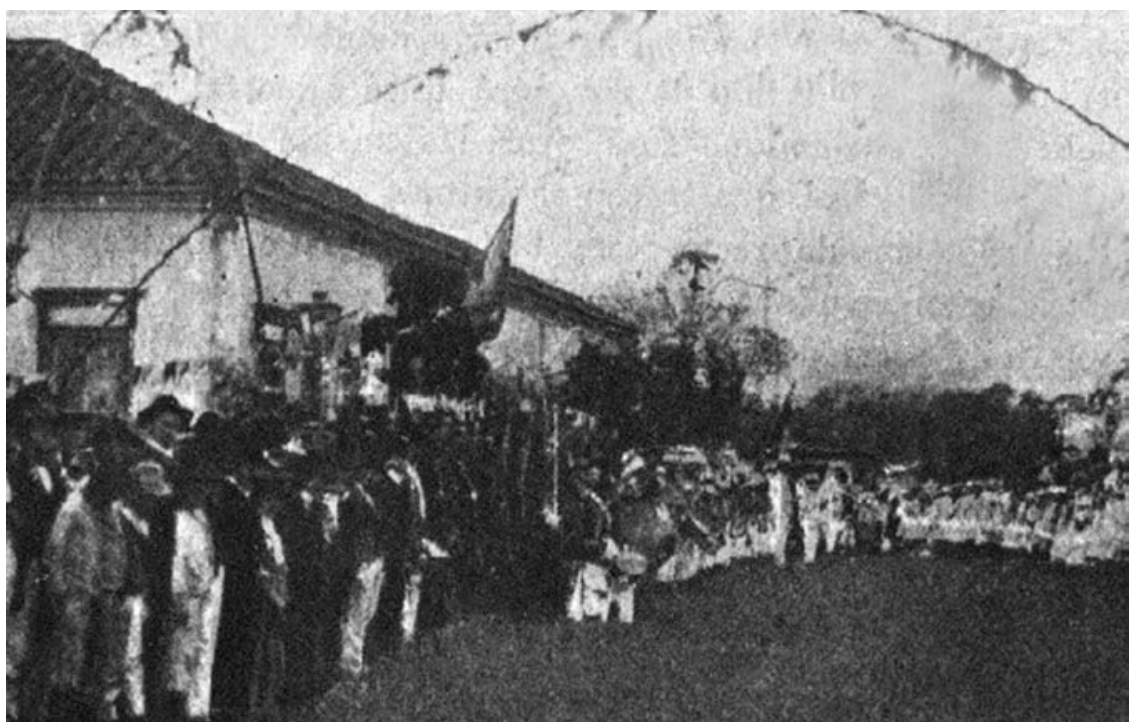

Impressão sobre papel: Álbum de Rio Preto 1918-1919. 8 cm X 10 cm. (foto D). 
Aspecto da cidade: A cidade, desde a vespera, apresentava um aspecto deslumbrante - todas as suas ruas ornamentadas de arcos, galhardetes e folhagens. Em frente às casas dos srs. Benedicto Lisbôa, Felipe Nasser, José Scaff e outros, a caprichosa disposição de arcos, o esmero de enfeites destes, harmonisavam-se em conjunto gracioso, digno de admirar-se.

Esse conjunto fotográfico agrupa visualmente documentos que, segundo F. Oiticica Lins, autor da seqüência histórica do Álbum de Rio Preto 19181919, são partes de documentações recolhidas no decorrer de suas atividades profissionais, conforme comenta na p. 8 desta obra:

Temo-nos valido, ao organisar este modesto trabalho de interesse todo regional, de notas tomadas a esmo, de documentos que nos têm vindo às mãos durante a nossa vida de advogado e de palestras com que nos costumamos entreter, ás vezes, com antigos habitantes da terra.

De todo esse conjunto, apenas uma fotografia foi aproveitada posteriormente para referenciar novamente o passado da cidade, e está presente nas pp. 131 e 132 da edição fac-similar do Album Illustrado da Comarca de Rio Preto $^{19}$, com o seguinte título: Rio Preto em 1912: a ultima visão de uma floresta extincta. A edição fac-similar dessa obra possui como única diferença do original o fato de apresentar paginação.

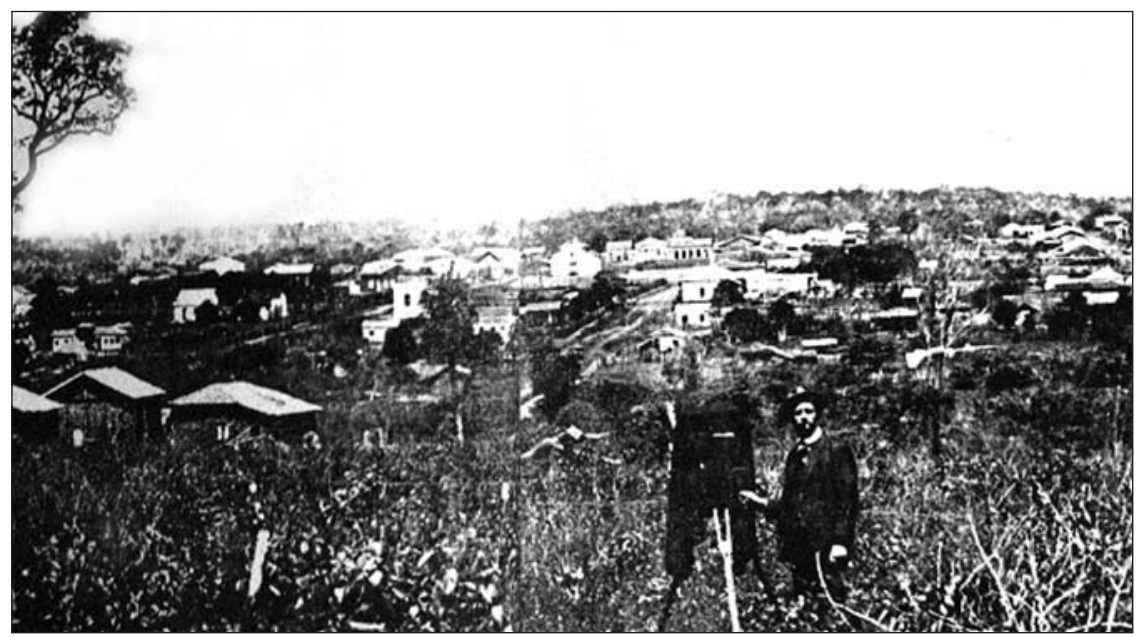

Impressão sobre papel: Álbum Illustrado da Comarca de Rio Preto 1927/1929. $16 \mathrm{~cm}$ $\mathrm{X} 32 \mathrm{~cm}$. (foto E). 
A fotografia central apresentada neste artigo (foto A) e as fotografias publicadas nos contextos dos álbuns analisados (fotos C e E) são basicamente a mesma imagem, mas existem diferenças em relação "ao recorte" do negativo original e à inserção de legendas explicativas no contexto da foto A.

$\mathrm{Na}$ foto A nota-se a inserção da legenda definindo o local (Rio Preto) e sua datação (1909). Afora isto, nas suas margens esquerda e direita há uma diminuição do tamanho, com a exclusão de ruas e casas presentes nas fotos $\mathrm{C}$ e E.

Do lado esquerdo da fotografia publicada no corpo do Álbum de Rio Preto 1918-1919 (foto C), e do Álbum da Illustrado Comarca de Rio Preto 19271929 (foto E), nota-se a presença de um conjunto maior de casas, levando a supor que a fotografia original, apresentada como foto A, foi ampliada com um "recorte" do negativo original.

Outro detalhe presente somente na fotografia impressa no Álbum Illustrado da Comarca de Rio Preto 1927-1929 (foto E) é a presença, no extremo esquerdo da imagem, de um suposto defeito adquirido do negativo original: uma pequena marca em forma de um laço, denunciando uma provável "falha” do mesmo, surgida aparentemente após sua publicação inicial, em 19181919 , pois esta suposta "falha" não aparece na imagem publicada no álbum datado dessa época.

$\mathrm{Na}$ foto A, o lado esquerdo também se encontra "recortado", talvez um ato para eliminar o defeito apresentado no negativo original, ou mesmo uma dificuldade de ampliação do negativo primário, que aparentemente era uma chapa de vidro, dada a câmara fotográfica presente na cena. Nota-se que de todas as fotografias (fotos A, C e E), a foto C é a que apresenta a maior abrangência visual, mostrando o tamanho real do negativo original.

O Album Illustrado da Comarca de Rio Preto 1927 -1929, conforme notado em seu subtítulo introdutório, é usado na Propaganda regional do Estado de São Paulo: Zona Araraquarense, assumindo um caráter de representatividade da cidade para o resto do Estado. Essa publicação nasceu da iniciativa de duas pessoas (Abílio Abrunhosa e Paulo Laurito) e é composta de 1153 páginas e cerca de mil fotografias. Em relação à autoria dessas imagens, encontra-se a seguinte referência na p. 408 desse álbum: "Theodoro Demonte: Photographo do Album e um dos esforçados companheiros com que contamos durante a organisação do mesmo." Theodoro Demonte foi um famoso fotógrafo da cidade no período.

Sobre a fotografia presente no Album Illustrado da Comarca de Rio Preto 1927 -1929 (foto E), escreveu a historiadora rio-pretense Dinorath do Valle, em 1999: "O município já tinha 18 anos quando Theodoro Demonte tirou esta foto do alto do bairro do Cemitério Velho (Maceno)." ${ }^{20}$ Tendo o municí- 
pio sido criado em 19 de julho de 1894 pela Lei 294, a historiadora admite 1912 como data da fotografia e Theodoro Demonte como seu autor.

Vários estudiosos da cidade aceitam tais datações e autorias sem maiores questionamentos, em razão de sua presença no famoso Álbum Illustrado da Comarca de Rio Preto 1927-1929. Para discutir datação e autoria, é necessário retomar a história da cidade.

São José do Rio Preto formou-se como cidade ainda na época do Império. Em uma das versões de sua fundação, comentada por Leonardo Gomes na primeira página de sua obra, João Bernardino de Seixas Ribeiro, mineiro da região da atual cidade de Ouro Preto, migrou em 1840 para o local conhecido como “(...) campos de Araraquares, na região oeste da província de São Paulo, onde (...) era concessionário de uma sesmaria obtida por ordem régia." Para Carlos Rodrigues Nogueira, na p. 12 de seu livro citado anteriormente, “(...) foi João Bernardino de Seixas Ribeiro que, tendo construído a primeira casa em 1852, de sapé, em meio ao lugar que lhe iria servir de invernada, foi, por isso mesmo, o legítimo e verdadeiro fundador do arraial". Outra versão, também assinalada por Nogueira, na página seguinte a do comentário anterior, diz respeito ao fato de as terras do patrimônio de São José, que deram origem à cidade, terem sido doadas para a Igreja por “(...) Luiz Antônio da Silveira e sua mulher, Dona Tereza Francisca de Jesus, por escritura particular de 19 de março de 1852, lavrada em Araraquara”.

Em sua passagem pelo então arraial de São José do Rio Preto, em 18 de julho de 1867, o visconde de Taunay, na época de seu retorno do cenário da Guerra do Paraguai, trouxe notícias da primeira versão, relacionando João Bernardino de Seixas e a cidade, descrevendo de forma detalhada a localidade na época:

Pousamos, por causa da grande tormenta, na única casa do arraial coberta de telha, pertencente ao Sr. João Bernardino de Seixas Ribeiro (...). A povoação consta de meia dúzia de palhoças abandonadas, na ocasião do recrutamento, por todos os habitantes que, com exceção do subdelegado, que era o próprio recrutador, haviam fugido para as matas e pontos em que se tornasse possível a exigência do serviço das armas. Há uma igrejinha em construção, e cremos que por muitos anos fique neste estado, quando não se arruíne totalmente. ${ }^{21}$

A “igrejinha”, comentada por Taunay, é o embrião daquela que aparece no centro das fotos A, C e E, e é a partir da mesma que se pode estabelecer uma datação aproximada para a imagem apresentada.

Da capela erguida pelo fundador e comentada por Taunay, há uma refe- 
rência recolhida por Carlos Rodrigues Nogueira nas pp. 179 e 180 da sua obra citada :

Quinze anos após este fato [1875], a vila de São José do Rio Preto recebia o seu primeiro vigário encomendado (...). Em 1879 (...) José Tavares e Joaquim Criôlo, escravos de João Bernardino, construiam a primeira Igreja, aproveitando a capela existente e reformando-a.

Provavelmente, a igreja presente nas fotografias analisadas (fotos A, C e E) é a mesma reformada pelos escravos de João Bernardino, pois não há notícias de outra construída entre 1879 e 1911.

Sobre esta igreja, Nogueira - nas pp. 78 e 79 de sua obra - comenta que o engenheiro Ugolino Ugolini,

(...) juntamente com Caetano Alves e Guilherme Aloisio Weber opinando sôbre as condições técnicas de resistência dos alicerces da igreja Matriz da cidade, dizia (...), em 26 de Outubro de 1911, dirigindo-se à Prefeitura Municipal: Actualmente ameaçam ruina e deveriam ser demolidas e substituidas por paredes de tijolos, se um tal conjunto pudesse satisfazer as actuaes necessidades da parochia e estar de accordo com o progresso architectonico desta cidade, devendo mesmo declarar que a conservação de um tal edificio seria um crime de lesa esthetica (...).

Nessa afirmação, percebe-se que a igreja encontrava-se em ruínas.

Segundo L. Arantes, citando F. Gil, autor de Diocese de Rio Preto (1943), a igreja começou a ser demolida “(...) em 15/04/1912 e um ano e meio depois (...), o padre Canto faz o lançamento da pedra fundamental para a construção da nova Matriz". ${ }^{22}$ Fato este também confirmado por Nogueira, nas pp. 179 e 180 de sua obra: "Em começo de 1912, a Prefeitura intimára (sic) o Padre Canto para demolir, em 90 dias, a igreja velha existente na cidade.” Estas afirmações depõem contra a datação da fotografia em 1912, pois não se detecta na imagem sinais de demolição.

Outro dado interessante é o artigo de Cândido Brasil Estrêla, presente na p. 15 da revista Centenário, em que o autor relembra Rio Preto em 1908, comentando que "(...) o largo da Matriz era um vassoural, raramente carpido (...).” Na imagem original apresentada, o campo à frente da igreja apresentase bem cuidado, diferente da afirmação de Brasil Estrêla.

Basileu Toledo França comenta, na mesma revista, na p. 97, também se referindo a 1908, que 
(...) duas providências importantes tiveram os nossos dirigentes: uma foi a lei 55 de fevereiro que mandava pôr sarjetas e abaular a rua Bernardino de Campos (...). Outra foi o ajardinamento da praça da matriz com planta e orientação do engenheiro Ugolino Ugolini. Vieram flores de S. Paulo e de Bebedouro.

Na observação das fotos $\mathrm{A}, \mathrm{C}$ e E, nota-se que o terreno defronte à igreja aparentemente está bem cuidado. Na fotografia, percebe-se apenas o terreno à frente da matriz limpo do mato, não se visualizando um ajardinamento. Questiona-se se este mesmo lugar não estaria sendo preparado para receber os melhoramentos citados por Basileu T. de França.

Se a fotografia fosse realizada em 1912, conforme argumentado por vários historiadores de Rio Preto, que se basearam nas informações presentes no Álbum Illustrado da Comarca de Rio Preto 1927 - 1929, o ajardinamento da praça já seria visível, pois, segundo Adolpho G. Corrêa, na p. 63 do referido álbum, "Tinhamos um jardim público — bem cuidado, com canteiros artisticamente dispostos em formas bizarras, tendo no centro um coreto vistoso e tendo ao redor um largo passeio de concreto(...).” Essa afirmação, aliada a uma fotografia desse jardim presente no Álbum de Rio Preto: 1918-1919, na p. 27, permite inferir que mesmo na distância oferecida pela fotografia central deste artigo, seria possível visualizar o citado ajardinamento.

Outro dado refere-se à presença da ferrovia, inaugurada em 9 de maio de 1912. Caso a fotografia tivesse sido realizada nesse ano, o edifício da estação seria visível, pois o mesmo é parte integrante da visualidade apresentada nas fotos A, C e E.

Impossibilitado de uma datação específica, a presença da inscrição 1909 na fotografia - anteriormente pertencente à senhora Amélia Rodrigues Goulart — não deve ser menosprezada.

Quanto à sua autoria, é possível questionar se foi realizada por Theodoro Demonte, visto que, segundo L. Arantes, na p. 130 de sua obra já citada, o fotógrafo só começou a atuar na cidade em 1917 e “(...) em 1918 montou ateliê de fotografia".

De acordo com Basileu Toledo França, na revista Centenário (p.103), analisando os primórdios da prática fotográfica em Rio Preto,

(...) o Sr. Lindolfo Corrêa montou o primeiro atelier fotográfico em Rio Preto nos fundos do atual Hotel Camareiro.(...) E os Drs. Ugolino Ugolini e Adolfo Guimarães Corrêa escreveram para a revista Cosmos [publicação da primeira Loja Maçônica da cidade] a página Photographia entre amadores sob o pseudônimo Daguerre, Le petit. 1901. 1902. Ensinamentos valiosos que serviram a muitos propagando no sertão a importante arte. 
Por estas afirmações, questiona-se: não seria o próprio Ugolino Ugolini a ser representado pelo próprio Adolfo G. Corrêa, ou vice-versa, como uma das possíveis experiências para sua coluna literária local? Tal fato torna-se impossível de ser respondido neste momento, mas é digno de nota, pois Adolfo G. Corrêa é personagem sempre presente quando relaciona-se o assunto à história da cidade. Nota-se que no Álbum de Rio Preto 1918-1919, ele é citado por Oiticica Lins, ao passo que no Álbum Illustrado da Comarca de Rio Preto 1927-1929, é o próprio Adolfo G. Corrêa quem escreve a parte histórica da referida publicação.

É possível que o(s) autor(es) da imagem seja(m) uns fotógrafo(s) itinerante(s). Essa questão da presença itinerante destes profissionais fotográficos, defendida por Boris Kossoy em seu recente trabalho, toma corpo quando se analisa um anúncio publicado em 1906, no Almanach D'Oeste do Estado de São Paulo, no qual se lê a seguinte propaganda:

The american C.R. Colortypes Company —Limited. Reprodução de Photographias em todos os systemas e tamanhos como sejam a Crayon, Sepia, Aquarella finissima, Pastel e Oleo, Cartões Postais, Retratos sobre porcelana, Esmaltes, etc. preços adimiraveis. Cesar Corain. _ agente geral para todo o Brasil. Guilherme 160 Votta — sub. agente nas comarcas de Araraquara, Jaboticabal, Bebedouro, Barretos e São José do Rio Preto. ${ }^{23}$

Nesse mesmo almanaque encontram-se diversos profissionais estabelecidos em Jaboticabal: Venancio Tomanini (p.75); Monte Alto: Hoff \& Nilzsche, e Mario Fornasario \& Comp. (p. 183); Ribeirãozinho (atual Taquaritinga): Domingos Marano (p.201); e Bebedouro: José Comparini e José Garcia (p. 224).

A referência mais concreta, e talvez a única, à atuação de um fotógrafo em São José do Rio Preto nesse momento é a encontrada no mesmo Almanach D' Oeste Do Estado De São Paulo, datado do ano seguinte, ou seja, 1907, na p. 337. Nessa obra, nota-se a menção a Luiz de Góes Pietschi, que se intitulava Photographo Amador. Sobre Pietschi, nada mais foi encontrado que mostrasse sua ligação com o material fotográfico recolhido. Sabe-se que além de fotógrafo, Pietschi foi o juiz de paz (1908/10). Seria este fotógrafo o autor da(s) imagem(s) apresentada(s)? Por que o uso do termo "amador" para referenciar sua identificação como fotógrafo?

$\mathrm{Na}$ análise formal do registro apresentado, percebe-se a atuação de dois fotógrafos na sua realização. O primeiro posa para a fotografia feita pelo segundo. A "atividade de fotógrafo" é referenciada pela presença de seu principal instrumento de trabalho, a câmera, e pelo objeto retratado ao fundo, a cidade. Dessa maneira, trabalham-se com duas referências para o processo. A 
primeira seria a do fotógrafo, posando para a imagem, tendo ao fundo a cidade. Nesse aspecto, enfatiza-se a questão da inserção do profissional no seu ambiente de atuação: seria como se o mesmo estivesse mostrando o sentido da sua atividade para a atração de possíveis fregueses. Tal atração seria concretizada pela presença de um elemento conhecido, a cidade vista ao fundo.

A segunda referência também seria de identificação e, neste caso, o fotógrafo realiza um trabalho para alguém, ou seja, registra a localidade de maneira a concretizar seu suposto reconhecimento visual. Este aspecto parece ser o menos provável, pois a forma de confecção da imagem, presença direta de um dos fotógrafos no registro, cria uma interferência relacionada à questão da identificação, pois torna-se necessário estabelecer pelo elemento visual conhecido, a cidade, um referencial de proximidade com o fotógrafo em questão.

Os aspectos apresentados são sintomáticos, pois mostram como a razão imagética de um local sobrepõe-se à lógica descritiva. Apela-se para a imagem de maneira a construir um referente que identifica e, ao mesmo tempo, possibilita a sua própria representação: criador e criatura vivem em relação simbiótica de identidade.

Retornando à questão do desenvolvimento urbano, vê-se que São José do Rio Preto é uma cidade na qual o modelo de ocupação reproduz a clássica relação de uma colonização entre rios. O núcleo urbano inicial, retratado na imagem, localiza-se entre os córregos do Borá e do Canela, correspondendo na atualidade às Avenidas Bady Bassitt e Alberto Andaló. Essa circunscrição correspondia ao antigo Patrimônio de São José e resume o embrião de desenvolvimento da cidade.

Formação urbana, alinhamento e formação de quadras, representam o clássico "tabuleiro de xadrez", que é fruto da tentativa de se criar na cidade elementos suficientes para revelar uma ocupação ordenada e, assim, refletir na mentalidade cotidiana aspectos condizentes com a sua concretização como urbe.

O traçado das ruas foi elaborado pelo engenheiro Ugolino Ugolini, membro da expedição de Olavo Hummel, responsável por estabelecer o traçado da chamada "Estrada Boiadeira" no governo de Américo Brasiliense, em 1893. Essa estrada ligou a cidade de Jaboticabal ao porto de Tabuado, passando por São José do Rio Preto, e foi fundamental para o escoamento do gado criado na região.

Carlos Rodrigues Nogueira, em sua obra na p. 76, cita Adolpho Guimarães Corrêa, prefeito da cidade entre 1908 e 1911:

A êle [Ugolino Ugolini] deve a cidade de São José do Rio Preto, além do traçado de suas ruas, aproveitado em 1910, e a reorganização do sistema de aforamento 
municipal, o seu traçado atual, o que lhe trouxe, própriamente, feição urbana, alguns melhoramentos públicos, como a planta dos terrenos do patrimônio, em 1895, e inúmeras sugestões preciosas, no campo da higiene e da urbanização, as quais, infelizmente, no tempo em que apresentadas, não foram tomadas na devida consideração pelo poder municipal.

$\mathrm{Na}$ análise clássica de Sérgio Buarque de Holanda,

(...) a cidade que os portugueses construíram na América não é produto mental, não chega a contradizer o quadro da natureza, e sua silhueta se enlaça a linha da paisagem. Nenhum rigor, nenhum método, nenhuma providência, sempre esse significativo abandono que exprime a palavra desleixo. ${ }^{24}$

Nessa afirmação percebe-se que o modelo de colonização inicial, adotado no país pelo português, girava em torno da não-organização. Estudos atuais relacionados ao urbano da cidade de São Paulo mostram como se fazia necessário modificar a paisagem urbana da capital, quando a mesma passou a ser uma espécie de vitrine da modernidade no País. Para tanto, basta lembrar a questão da esquina “Quatro Cantos” em São Paulo, que, nas últimas déca162 das do século XIX representava o ápice deste alinhamento urbano, justamente por apresentar o único cruzamento (Rua Direita com Rua de São Bento) em ângulos retos da cidade..$^{25}$

$\mathrm{Na}$ afirmação de Adolpho C. Guimarães, referida anteriormente, nota-se esta preocupação com a organização espacial da cidade: “(...) o seu traçado atual, o que lhe trouxe, propriamente, feição urbana (...)”. Vê-se, assim, que era motivo de orgulho a forma em "tabuleiro de xadrez" apresentada. A representação de São José do Rio Preto nas fotos A, C e E é sintomática, pois percebe-se o alinhamento de suas ruas e a distribuição regular das quadras.

Segundo o historiador rio-pretense Agostinho Brandi, dois fatos significativos marcariam o traçado urbano da cidade. O primeiro, em 1859, quando a Câmara de Araraquara, em sessão do dia 5 de janeiro de 1859, propôs

(...) que esta Câmara nomeasse uma comissão de dois cidadãos probos e residentes na Capella do Rio Preto para, de acordo com o arruador da mesma Capella marcasse o arruamento da mesma povoação de acordo com as Posturas Municipais (.... ${ }^{26}$

O outro, também citado pelo autor, refere-se ao ano de 1879, quando a sessão da Câmara de Jaboticabal de 19 de maio requeria que fosse "(...) nomeada uma comissão para traçar o quadro do pátio e arruamento da Fregue- 
sia do Rio Preto (...).” Para Ary França, ao citar Pierre Monbeig, comentando a região de São José do Rio Preto:

(...) cada cidade é uma réplica de sua vizinha. As condições geográficas não são geradoras de paisagens urbanas diferentes, assim como, em sua perfeita igualdade, não o são na origem dos diferentes destinos do patrimônio. Os homens são os únicos responsáveis pelos destinos desiguais de suas obras urbanas. ${ }^{27}$

Pode-se dizer que São José do Rio Preto representa, no momento da fotografia reproduzida, a busca da organização de um traçado urbano que possa estabelecer uma ligação pertinente com a proposta de desenvolvimento citadino.

Desde 1898, a Câmara Municipal busca ordenar o traçado urbano, pois de acordo com a Ata da Câmara Municipal de 4 de outubro, no

(...) parecer da commisão de Obras Publicas: A commissão de Obras Publicas é de parecer que seja deferido o requerimento apresentado pelo comendador e submete a Camara o seguinte projecto Lei no 19 _ Art. $1^{\circ}$ é permitido a construcção de Cazas de alturas de quatorze palmos de pé direito fora do quadro e alem da rua Boa Vista; _ Art. $2^{\circ}$ Fica o Intendente autorizado a ispecificar as demais ruas e lugares onde possão serem construidas as mesmas cazas; $A r t .3^{\circ}$ quanto as dicisões de portas e janellas, serão em votação a altura das mesmas cazas para que fique em simetria (...).

Percebe-se, assim, a preocupação com o crescimento da cidade para além do núcleo histórico original. A Rua Boa Vista pertencia ao Patrimônio de Nossa Senhora do Carmo, estando na parte nova da urbe, segundo o traçado do primeiro Mappa da Villa de São José do Rio Preto, de autoria do engenheiro Ugolino Ugolini, realizado entre 1893 e 1894 . Ainda nesse aspecto, é sintomático que antes de pleitear a condição de município, na mesma época, a pedido do padre José Bento da Costa, Ugolino Ugolini elabore a primeira planta urbana de São José do Rio Preto.

De acordo com Agostinho Brandi, no artigo anteriormente citado,

Foi nas primeiras décadas da fase distrital de Rio Preto, 1852 a 1894 (distrito de Araraquara 1852/67 e de Jaboticabal 1867/94) que se moldou o traçado definitivo de suas vias públicas, cuja configuração geométrica marcou para sempre o perfil do centro original, o núcleo urbano propriamente dito, localizado no Patrimônio de São José, entre os córregos Borá e Canela 


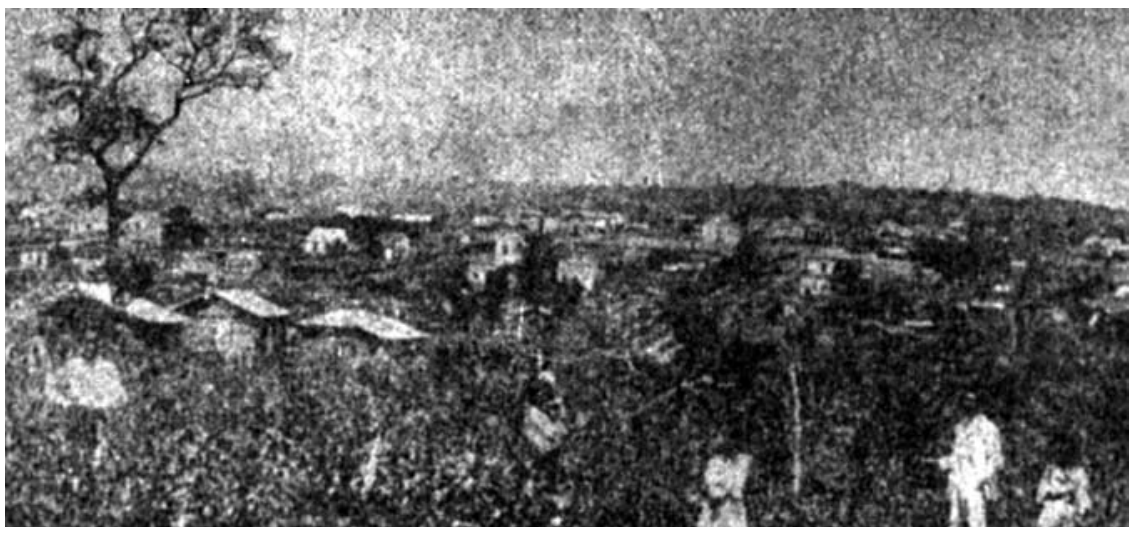

Impressão sobre papel: Revista Centenário: 7,4 cm X $20 \mathrm{~cm}$ (foto F)

Essa conformidade geométrica mostra a organização das ruas locais, estabelecendo diretrizes importantes para análise da fotografia apresentada.

Tradicionalmente, a fotografia - centro deste artigo (foto A) - é descrita como tendo sido feita do atual bairro da Maceno, em direção ao centro, sentido NE-SO. De fato, essa suposta visão privilegiada da urbe é aproveitada em outra imagem do período, que também foi realizada, aparentemente, do mesmo local. Sobre essa fotografia também não há referência direta de seu(s) produtor(es), apenas é usada como ilustração, corroborando um texto sobre a história da cidade.

Essa imagem aparece com a seguinte legenda, na revista Centenário, na p. 91: "Vista panorâmica da cidade, tirada do alto da Vila Maceno, em 1904 provavelmente." Segundo o editor da revista Centenário, o senhor Orlando Cal: "As fotografias foram trazidas pelo próprio Basileu Toledo França para preparação para impressão. Depois ele as levou embora.” (Orlando Cal, entrevista concedida em 7/7/2001). Nota-se pela argumentação do senhor Orlando Cal que a imagem era de posse particular de Basileu T. França, autor do texto sobre a história da cidade.

Nesta fotografia, é possível verificar que o conjunto de árvores à esquerda é o mesmo das fotos A, C e E. Percebe-se, também, que o enquadramento fotográfico da cidade no local proporcionava uma visualidade quase total da urbe. Provavelmente, a ausência de outra plataforma arquitetônica que abrangesse de modo significativo o urbano de Rio Preto, como a torre da igreja, por exemplo, transformava essa elevação natural do terreno em um ótimo local de onde retratar a cidade.

Em 1895, o engenheiro Ugolino Ugolini começou a escrever uma Mono- 
graphi $^{28}$ sobre a cidade de São José do Rio Preto para o jornal Correio do Sertão, de Jaboticabal, na qual descreve a localidade e fornece detalhes da sua constituição urbana, climática e social. Esse material é de extrema importância pois, aparentemente, é o único restante desse período da história da cidade.

O autor, no jornal do dia 31 de março de 1895, na p. 1, descreve a localidade, afirmando que continha "(...) principalmente do lado SO, immensas mattas virgens das melhores madeiras e a NE cerrados e campos de criação”. No dia 4 de abril do mesmo ano, no mesmo jornal, na p. 2, Ugolino Ugolini comenta sobre os limites da então vila de São José do Rio Preto:

(...) A villa é circunscripta a N.E. pelo Rio Preto - nome mal apropriado, porque as suas aguas são limpidas e o leito não é preto, alem de que o volume da agua é mais de um ribeirão que de um rio, desaguando no Turvo e não no Rio Grande. A N.O. é cincunscripta pelo corrego da Piedade, a S.O. por uma rua (da futura Santa Casa) de 2 kilom. e 645m., e a S.E. pelo corrego da Canella.

A distribuição geográfica relatada por Ugolini mostra como a visualidade das fotos A, C e E foi constituída e determina a direção da composição da imagem. Nota-se ao fundo da imagem, após a igreja, uma grande quantidade de mata, provavelmente aquela descrita pelo autor estando a SO da vila. No local em que está o fotógrafo, percebe-se um pequeno cerrado que identifica o lado NE. Por estes dados, pode-se perceber que o fotógrafo realizou a imagem na direção $\mathrm{NE}$ - SO, corroborando a afirmação tradicional quanto ao local de elaboração dessa fotografia, na região da atual Vila Maceno.

Na disposição visual apresentada pela fotografia, observa-se a distribuição geográfica da urbe. Do seu lado direito, encontra-se a região do Patrimônio de Nossa Senhora do Carmo e o córrego do Borá (atual Av. Bady Bassit); do seu lado esquerdo está o córrego do Canela (atual Av. Alberto Andaló) e, na época, o início da estrada para Jaboticabal. No centro da fotografia, a depressão aparente refere-se ao rio Preto, sendo o começo da estrada para Bebedouro e Barretos. É possível, também, identificar na fotografia publicada no Álbum Illustrado da Comarca de Rio Preto 1927-1929 (foto E), duas ruas centrais. A primeira, na extrema direita, é a Rua do Commercio (atual General Glicério), e a outra, passando ao lado da igreja, a Adolpho Guimarães (atual Bernardino de Campos). A cidade que se vê ao fundo possuía 4.836 habitantes, segundo o Mappa demonstrativo do desmembramento e creação dos municipios paulistas no período de 1829 a 1905, elaborado por Affonso A. de Freitas. ${ }^{29}$

Outras notícias sobre a cidade no período são relacionadas ao seu desenvolvimento material. Sabe-se, por exemplo, por afirmação de Basileu T. França, na revista Centenário na p. 97, que “(...) em 1907 tinha início a coleta de 
lixo em nossa cidade, em que a prefeitura empregava uma carroça e um homem gastando por mês a quantia de $150 \$ 000$ ”. Ainda nas recordações do autor, na página anterior da mesma publicação, “(...) em 28 de dezembro de 1908 inaugurava-se entre nós a primeira rede de 15 aparelhos da Empresa Telephonica (...)".

Desse período, é possível analisar a receita de arrecadação municipal, que evoluiu consideravelmente entre os anos de 1904 (data da criação do município) e 1912 (época da chegada do trem). No ano de 1904, o município possuía como receita $24: 237 \$ 700$, ao passo que para 1908 , a arrecadação subia para 46:820\$000. No ano seguinte, em 1909, a arrecadação era de 75:460\$000, e em 1912, a receita saltava para 121:000\$000 (estes dados estão presentes na p. 101 da revista Centenário). Ainda em 1908, segundo Odilon Nogueira de Matos, conforme citação anterior, a estrada de ferro, estacionada em Taquaritinga desde 1901 — em razão de uma crise econômica relacionada à baixa do preço do café - voltou a ser construída, chegando a Fernando Prestes, a cerca de $100 \mathrm{~km}$ de Rio Preto.

Questiona-se, assim, se a produção destas imagens relacionadas à cidade e ao seu urbano são reflexos do panorama socioeconômico do período e uma conseqüência direta da busca de uma identidade própria, necessária à admi166 nistração municipal, ou mesmo aos membros de uma elite dirigente no período. Concorrendo com esta idéia, pode-se destacar que Adolpho Guimarães Corrêa — o mesmo que escrevia em 1902 em conjunto com Ugolino Ugolini uma coluna na Revista Cosmos relacionada à prática da fotografia foi prefeito do município entre 1908 e 1911, demonstrando uma estreita ligação entre os elementos gestores do município e os responsáveis pela divulgação e sedimentação da história de São José do Rio Preto.

A fotografia central deste artigo pode demonstrar, pela forma como o personagem principal "apresenta" a cidade ao observador, um flagrante de posse das estruturas ou identificação com o local escolhido para representação.

Susan Sontag, após discorrer sobre a fotografia como forma de comprovar a experiência do ato de estar em algum lugar, convertendo a imagem “(...) numa recordação (...)", sintetiza: "A fotografia tornou-se um dos principais meios de acesso à experiência fotográfica, (...) uma ilusão de participaçãa. . $^{30}$ ” É nesta ilusão de participação que se vê uma necessidade de inserção por parte dos autores/personagens. A cidade em si representa uma ligação com algo conhecido. Ela, assim, torna-se o elemento de identidade.

Nota-se, em um primeiro momento, no ato da publicação do Álbum de 1918-1919, que a imagemcentraldesteartigo, emconjuntocomasoutrasfotografias da obra, serviu a um propósito de simples ilustração do que era a cidade, corroborando a história da urbe narrada. No segundo olhar, já em 
1929, com a publicação do Álbum Illustrado da Comarca, obra de maior circulação cuja impressão atingiu 5 mil exemplares, a mesma imagem serviu para ilustrar o passado a ser esquecido, algo a ser negado diante das perspectivas de "progresso" e "civilização" desenvolvidas para a cidade. No texto que acompanha a imagem, o autor, não identificado, comenta nas pp. 131 e 132 sobre a mesma:

Realmente, o que nos conta a gravura abaixo é bem um resumo da typica indolencia que caracterizou o progresso de Rio Preto até áquella data. O matto retalhado em fraldas largas, envolvia ainda nos seus refôlhos, a minuscula cidade que se espraiava timidamente por entre cerros alcatifados de vegetação abundante./ Desde o centro, onde reluzia esforçadamente a minuscula capella de São José, como um lençol de bretanha esquecido sobre um eirado descompôsto, tudo era matto. / Matto intenso, matto convulso, enredando na sua trama a vida insipiente de uma cidade em ensaios.

Percebe-se desta maneira a imagem sendo usada como forma de negação do que era a cidade antes, e isto cerca de vinte anos após a realização da mesma. Em pouco tempo, a memória foi substituída pela comparação direta entre o passado e o presente. Destaca-se que o Álbum Illustrado da Comarca de Rio Preto 1927-1929 é constituído basicamente de reportagens fotográficas sobre São José do Rio Preto, retratando o momento de sua publicação, formando, para a posteridade, a base da memória visual do passado da urbe.

A construção imagética do urbano de Rio Preto condicionou-se às tentativas de esquecimento do passado, para assimilação de novos e constantes contextos relacionados ao seu suposto desenvolvimento e progresso. Essa exaltação contínua do progresso mostra uma necessidade de afirmação do presente como único elemento passível de permanência e recordação. Tal fato recria a memória de maneira a negar-se todo o passado não condizente com a proposta desenvolvida para o momento. No Álbum Illustrado da Comarca de Rio Preto 1927-1929 tem-se a substituição deste mesmo passado, que é negado quando a imagem que o representa é tratada como “(...) Matto intenso, matto convulso, enredando na sua trama a vida insipiente de uma cidade em ensaios”. Essa imagem é a negação de um passado que não se harmoniza com a realidade da época. Enfoque diferente apresenta o Álbum de Rio Preto 19181919, no qual não há nenhum texto criticando o passado ilustrado por fotografias, ao contrário, a parte histórica é corroborada pela presença das imagens que retratam o passado da urbe. 


\section{NOTAS}

${ }^{1}$ MÜLLER, Daniel P. Mappa Chorographico da Provincia de São Paulo. Paris: Aleixo Orgaizzi, 1837; MELLO, Barão Homem de e MELLO, Dr. Francisco Homem de. Atlas do Brazil. Rio de Janeiro: F. Briguiet \& Cia., 1909.

${ }^{2}$ COSTA, Luiz Flávio de C. O caminho de São Bento de Araraquara. ALMEIDA,A.M.; ZILLY,B.; LIMA,E.N. (orgs.). De sertões, desertos e espaços incivilizados. Rio de Janeiro: MAUAD/FAPERJ, 2001, p.113.

${ }^{3}$ GOMES, Leonardo. Gente que ajudou a fazer uma grande cidade: Rio Preto. São Paulo: gráfica São José, 1975; NOGUEIRA, Carlos Rodrigues. São José do Rio Preto: 1852 —1945. São Paulo: João Bentivegna. 1952.

${ }^{4}$ KOSSOY, Boris. Dicionário Histórico de fotógrafos e do ofício fotográfico no Brasil (18401910). Tese de livre Docência apresentada na Escola de Comunicação e Artes da Universidade de São Paulo, 2000. Tomo I, p. 36.

${ }^{5}$ MARQUES, Abílio A.S. Indicador de São Paulo: administrativo, judicial, industrial, profissional e commercial para o anno de 1878. São Paulo: Typ. de Jorge Seckler, 1878, p. V.

${ }^{6}$ ALMANAK ADMINISTRATIVO, MERCANTIL E INDUSTRIAL DA PROVÍNCIA DE SÃO PAULO para o anno de 1857, $1^{\circ}$ anno. Organizado por Marques \& Irmão. São Paulo: Typographia Imparcial de J.R. Azevedo Marques, 1856; ALMANACH DA PROVINCIA DE 168 SÃO PAULO. Organizado por Jorge Seckler. São Paulo, Jorge Seckler \& Comp, [s.d.]. Seriado. $1885-1888$.

${ }^{7}$ Álbum de Rio Preto: 1918-1919. Rio Preto: Irmãos Giovinazzo, p.11.

${ }^{8}$ MATOS, Odilon Nogueira de. Café e Ferrovias: a evolução ferroviária de São Paulo e o desenvolvimento da cultura cafeeira. Campinas: Pontes, 1990, p.133.

${ }^{9}$ ARRUDA, Gilmar. Cidades e Sertões: entre a história e memória. Bauru-SP: EDUSC, 2000, p.99.

${ }^{10}$ KOSSOY, Boris. Estética, memória e ideologia fotográfica: decifrando a realidade interior das imagens fotográficas. In: Acervo: revista do Arquivo Nacional, Rio de Janeiro: v. 6, n.1/2, jan./dez. 1993, p.18.

${ }^{11}$ CAPRI, Roberto. O Estado de São Paulo e seus municípios. São Paulo: Typ. POCAI \& WEISS, 1913 - (seriado).

${ }^{12}$ KOSSOY, Boris. Realidades e ficções na trama fotográfica. São Paulo: Ateliê Editorial, 1999, p. 41.

${ }^{13}$ MÜLLER, Daniel Pedro. Ensaio d’um quadro estatístico da província de São Paulo. $3^{\mathrm{a}}$ ed. fac-similada. São Paulo: governo do Estado, 1978, p. XXXV.

${ }^{14}$ GODOY, Joaquim Floriano de. A Província de São Paulo: trabalho estatístico, histórico e noticioso. Ed. fac-similar. São Paulo: governo do Estado, 1978.

${ }^{15}$ MARQUES, M.E. de Azevedo. Província de São Paulo. São Paulo: Itatiaia/EDUSP, 1980, pp. 213-214, v.II.

Revista Brasileira de História, vol. 23, nº 46 
${ }^{16}$ ALMANAK ADMINISTRATIVO, MERCANTIL E INDUSTRIAL DA PROVÍNCIA DE SÃO PAULO para o anno de 1857, $1^{\circ}$ anno. Organizado por Marques \& Irmão. São Paulo: Typographia Imparcial de J.R. Azevedo Marques, 1856, p. 167.

${ }^{17}$ LINS. M.J. de Albuquerque. Mensagem enviada ao Congresso Legislativo a 14 de julho de 1909. São Paulo: Duprat \& Comp., 1909, p. 35.

${ }^{18}$ Centenário: revista comemorativa do I centenário da fundação de São José do Rio Preto. FRANÇA, Basileu Toledo(org.). São José do Rio Preto: Casa Cal ed., 1952, p. 29.

${ }^{19}$ Álbum Illustrado da Comarca de Rio Preto. Abilio Abrunhosa Cavaleiro (org.). São Paulo: Casa Editora Duprat/ Mayença. 1927/1929 (ed. fac-similar). Nota: a edição original desta mesma obra não apresenta paginação.

${ }^{20}$ VALLE, Dinorath do. Diário da Região: Cidades. 18 de julho de 1999, pp. 4-5.

${ }^{21}$ TAUNAY, Visconde de. Viagens de Outrora. São Paulo: Melhoramentos. 1948, p. 106.

${ }^{22}$ ARANTES, L. Dicionário Rio-Pretense. Rio Preto: Editora Rio-Pretense, 1997, p. 93.

${ }^{23}$ ALMANACH D' OESTE DO ESTADO DE SÃO PAULO: abrangendo as comarcas de Jaboticabal e Bebedouro. $3^{\circ}$ ano, organizado por Guilherme Votta. São Paulo: Typ. Americana, 1906, p. 258.

${ }^{24}$ HOLANDA, Sérgio Buarque de. Raízes do Brasil. 16. ed. Rio de Janeiro: José Olympio, 1983, p. 76.

${ }^{25}$ Para maiores detalhes ver: CAVENAGHI, Airton José. Imagens que falam: olhares fotográficos sobre São Paulo (Militão Augusto de Azevedo, e "São Paulo Light and Power Co.", fins do século XIX e início do século XX). Dissertação de Mestrado. São Paulo: FFLCH/USP, 2000, pp. 112-113.

${ }^{26}$ BRANDI, Agostinho. O traçado de Rio Preto. Diário da Região. S.J. do Rio Preto - SP: caderno Cidade, 31 de janeiro de 2001, p.4.

${ }^{27}$ FRANÇA, Ary. A marcha do café e frentes pioneiras. Rio de Janeiro: Conselho Regional de Geografia, 1960, p. 199.

${ }^{28}$ Correio do Sertão. Jaboticabal, 17/3/1895, p. 2.

${ }^{29}$ FREITAS, Affonso A. de. Geographia do Estado de São Paulo(...). São Paulo: Escolas Profissionaes Salesianas, 1906, p. 48.

${ }^{30}$ SONTAG, Susan. Ensaios sobre fotografia. Lisboa: Dom Quixote, 1986, p. 20 (grifo nosso).

Artigo recebido em 2/2002. Aprovado em 10/2003. 